\title{
Glycerol-induced Hemoglobinuric Acute Renal Failure in the Rat. I. Micropuncture Study of the Development of Oliguria *
}

\author{
Donald E. Oken, $\dagger$ Manuel L. Arce, $\$$ and Douglas R. Wilson $\S$ \\ (From the Departments of Medicine, Peter Bent Brigham Hospital and Harvard Medical \\ School, Boston, Mass.)
}

The oliguria of acute renal failure has been attributed to tubular obstruction (1-12), "leakage" of the glomerular filtrate through rents in the tubular wall (13-19), and vascular mechanisms of various types (20-25). In a previous paper, it was shown that the oliguria of mercury-induced acute renal failure in the rat reflects a primary decrease in glomerular filtration rate and cannot be attributed to tubular mechanisms (26). The applicability of these findings to most types of acute renal failure occurring in humans may be questioned, however, because of the very dissimilar etiologies and the known effect of large doses of mercury on the renal circulation (27). The present study concerns the events leading to the development of oliguria in glycerol-induced hemoglobinuric acute renal failure, a model more closely akin to the syndrome of acute renal failure in man.

\section{Methods}

Sprague-Dawley and Cobb female rats weighing approximately $200 \mathrm{~g}$ were placed in metabolic cages for at least 1 day before experimentation. Their consumption of food and water (allowed ad libitum) as well as their weight changes and urine output during this time were recorded. Rats designated as "dehydrated" were given free access to food but deprived of drinking water for 24

* Submitted for publication November 12, 1965; accepted January 20, 1966.

Supported by grants AM 05505 and AM 08695 from the National Institutes of Health.

Presented in part at the Annual Meeting of the American Federation for Clinical Research, Atlantic City, N. J., 1965.

$\dagger$ Address requests for reprints to Dr. Donald E. Oken, Peter Bent Brigham Hospital, 721 Huntington Ave., Boston, Mass. 02115.

$\$$ Former fellow of the Consejo Nacional de Investigaciones Cientificas y Tecnicas, Argentina. Present address: Lemuel Shattuck Hospital, Boston, Mass.

$\S$ Research fellow of the American College of Physicians. hours before glycerol injection. They lost an average of $8 \%$ of body weight in the period of dehydration, during which time their food intake was one-third less than that of nondehydrated animals. Blood samples were obtained by cardiac puncture from a number of glycerolinjected animals and dehydrated control rats that were exempted from micropuncture studies to determine the change in their blood urea nitrogen (BUN) occurring over a 48 -hour period. BUN was measured on $0.2-\mathrm{ml}$ samples by a modification of the urease method of Gentzkow (28). Urinary osmolalities were determined with an Advanced osmometer.

Acute renal failure was induced by injecting $50 \%$ glycerol in water into the muscle of both hind limbs at a total dose of $10 \mathrm{ml}$ per $\mathrm{kg}$ of body weight. Within 2 hours after this injection, the urine was found to be burgundy red in color due to the presence of heme pigments.

The animals were subjected to micropuncture experiments at times ranging from 30 minutes to 26 hours after glycerol injection. They were anesthetized with sodium pentobarbital given intraperitoneally at a dose of 40 to $50 \mathrm{mg}$ per $\mathrm{kg}$ body weight. Their blood pressure was monitored as described earlier (26) either by a tail cuff microphone method or intra-arterial manometry. Although hypotension typically did not occur, animals whose mean arterial blood pressure was less than 85 $\mathrm{mm} \mathrm{Hg}$ were excluded from micropuncture study. The left kidney was exposed through an abdominal incision and carefully dissected free of the perirenal fat. The renal hilus was disturbed as little as possible, and the renal capsule was left intact. The kidney was placed in a Lucite holder to minimize its displacement with respiration. Its surface was covered with warm mineral oil to prevent drying and to aid in visualization of the renal structures.

Micropuncture methods were those described in an earlier paper (26). In short, proximal tubular hydrostatic pressure was measured by a modification of the manometric method of Wirz (29), using a water manometer to obtain maximal definition of the end point. The manometer was calibrated at zero pressure before each measurement. Glomerular filtration rate and fractional water absorption were determined at least 30 minutes after the injection of $40 \mu \mathrm{c}$ of ${ }^{14} \mathrm{C}$-labeled inulin ${ }^{1}$ in 0.3 to $0.5 \mathrm{ml}$ of $140 \mathrm{mM} \mathrm{NaCl}$. Labeled inulin, $130 \mu \mathrm{c}$ per $5 \mathrm{ml}$

1 New England Nuclear Corp., Boston, Mass. 
saline, was injected intravenously at a rate equal to the predicted inulin excretion rate immediately thereafter and throughout the micropuncture experiments, using a Braun microperfusion pump and siliconized precisionground syringes. Proximal tubular fluid was collected with small well-beveled pipettes, and the usual precautions were taken against fluid leakage at the puncture site. Collections were made at a rate closely approximating spontaneous flow rate as previously described (26), the time of collection being measured to the nearest second. The puncture site in the proximal tubule was determined by the intratubular injection of latex and subsequent microdissection of the nephron, as described by Bott (30). Sample volumes were measured in a precalibrated, $0.2 \mathrm{~mm}$ i.d. constant bore capillary tube, with meniscus error minimized and evaporation prevented by filling the tip of the capillary tube with a $7: 3$ mixture of chloroform and liquid silicone. Samples varied in size from 0.01 to $0.08 \mu 1$, and those smaller than $0.015 \mu \mathrm{l}$ were discarded because of the possibility of excessive measurement error in such small samples. Before and after each tubular fluid collection, a $0.1-\mathrm{ml}$ blood sample was taken from the tail for determination of the plasma inulin${ }^{14} \mathrm{C}$ concentration. Radioactivity was measured in a Nuclear-Chicago liquid scintillation counter at an efficiency of $60 \%$. Glomerular filtration rate of individual nephrons was determined from the plasma concentrations and the timed excretion of ${ }^{14} \mathrm{C}$-labeled inulin. Fractional water absorption was determined from the tubular fluid to plasma inulin $-{ }^{14} \mathrm{C}$ concentration ratio $\left(\mathrm{TF} / \mathrm{P}_{\mathrm{In}}\right)$ without correction for the water content of plasma.

Direct qualitative estimates of proximal tubular water absorption were made in a number of experiments without relying on the assumption of tubular impermeability to inulin. In these experiments, a drop of Sudan blackstained mineral oil was injected into the proximal tubule and allowed to pass distal to the pipette tip. A second oil droplet was injected rapidly in such a way that a short segment of tubular fluid was trapped between the two droplets. This maneuver was difficult in tubules with adequate flow, since the droplets tended to be washed rapidly away, but it could be readily accomplished in tubules with reduced flow. By aspirating the propelling tubular fluid as it reached the pipette the oil droplets were held stationary long enough for us to observe the rate of absorption of the trapped segment of tubular fluid. Without resorting to serial photographs, estimates of this type are necessarily inexact. We made only gross estimates of water absorption, therefore, and judged absorption assessed by the rate of disappearance of the segment of tubular fluid to be minimal or absent, moderately decreased, or indistinguishable from normal.

Frequently, after the injection of glycerol, tubular fluid flow rates were too slow to permit the collection of a sample of proximal tubular fluid large enough for accurate measurement. To obtain an estimate of the rate of flow in such tubules, we injected a drop of Sudan blackstained mineral oil, approximately 1 tubular lumen diameter in length, into proximal tubules. Flow rate was estimated qualitatively by observing the rate at which the oil droplet moved down the nephron. In both normal tubules and those with decreased fluid flow rates, such oil droplets passed freely along the tubule. Reasonable qualitative correlation was found between flow rate estimated in this way and flow rate measured by volume collection, although small differences in flow could not be detected by the eye.

\section{Results}

Rats given free access to water in the 24 hours before glycerol injection drank an average of $34 \pm$ 5 (SE) $\mathrm{ml}$ water and excreted $7 \pm 1 \mathrm{ml}$ urine during this time. In the 24-hour period after glycerol injection, their mean water intake was $23 \pm 2 \mathrm{ml}$ and urinary volume averaged $8 \pm 2 \mathrm{ml}$. Oliguria, defined as the excretion of less than $3 \mathrm{ml}$ of urine in 24 hours, was found in $30 \%$ of the animals of this group. The BUN concentration measured in a series of 24 of these 41 rats rose from a control mean value of $13 \pm 0.4(\mathrm{SE})$ to $64 \pm 49$ $\mathrm{mg}$ per $100 \mathrm{ml}$ (range 13 to $227 \mathrm{mg}$ per $100 \mathrm{ml}$ ) in 48 hours. Twenty-three of 27 rats deprived of water for 24 hours before glycerol injection developed oliguria or anuria that lasted at least 24 hours. Sixteen of these rats were totally anuric, and five had urinary volumes of less than $1 \mathrm{ml}$ per 24 hours. Their mean BUN concentration during the control period was $13 \pm 1 \mathrm{mg}$ per $100 \mathrm{ml}$, and it rose to $222 \pm 13 \mathrm{mg}$ per $100 \mathrm{ml} 48$ hours afterward.

The urinary volume of 75 rats that were deprived of water for 24 hours but did not receive glycerol averaged $1 \pm 0.2(\mathrm{SE}) \mathrm{ml}$. The urine of these rats was maximally concentrated to a mean osmolality of $2,910 \pm 27 \mathrm{mOsm}$ per $\mathrm{kg}$. When water deprivation was continued for a total of 72 hours, the BUN concentration rose minimally to $17 \pm 1 \mathrm{mg}$ per $100 \mathrm{ml}$. By contrast, 27 dehydrated rats receiving glycerol excreted urine with a mean osmolality of $1,506 \pm 162 \mathrm{mOsm}$ per $\mathrm{kg}$ in the 48-hour period after injection, a value significantly lower than that of dehydrated control rats $(p<0.001)$. Most of these animals did not drink sufficient water in the 24-hour period after glycerol to reattain their original weight. Two of the three rats that drank sufficient water to reachieve their predehydration weight, however, were totally anuric, and the third animal excreted $1 \mathrm{ml}$ urine during this period. The BUN concentrations of these rats were 230,254 , and $145 \mathrm{mg}$ per $100 \mathrm{ml}$, respectively, 48 hours after glycerol injection. 
TABLE I

Change in the appearance of the kidney surface during the first 26 hours after glycerol injection*

\begin{tabular}{|c|c|c|c|}
\hline \multirow[b]{2}{*}{ Time } & \multirow[b]{2}{*}{ Change } & \multicolumn{2}{|c|}{$\begin{array}{l}\text { Fraction of tubules } \\
\text { involved }\end{array}$} \\
\hline & & $\begin{array}{l}\text { Nonde- } \\
\text { hydrated }\end{array}$ & $\begin{array}{l}\text { Dehy- } \\
\text { drated }\end{array}$ \\
\hline 5 to 10 minutes & $\begin{array}{l}\text { Marked pallor with decrease in peritubular capillary } \\
\text { circulation, decrease in size of tubular lumina, and pale } \\
\text { tubular epithelium despite normal blood pressure. }\end{array}$ & & \\
\hline $\begin{array}{l}15 \text { to } 30 \text { minutes } \\
\text { (30 to } 45 \text { in } \\
\text { dehydrated rats) }\end{array}$ & $\begin{array}{l}\text { Hemoglobin-stained fluid first appears in tubular lumina. } \\
\text { Peritubular capillary circulation improving. }\end{array}$ & & \\
\hline 1 hour & $\begin{array}{l}\text { All tubular lumina contain red fluid, tubular epithelium } \\
\text { pale and granular, and tubular flow rate reduced. }\end{array}$ & & \\
\hline $\begin{array}{l}2 \text { to } 4 \text { hours } \\
\text { ( } 3 \text { to } 4 \text { in } \\
\text { dehydrated rats) }\end{array}$ & $\begin{array}{l}\text { No visible lumina, granular epithelium, absent flow. } \\
\text { Variable size lumina, red fluid, granular epithelium, } \\
\text { reduced flow rate. Peritubular capillary circulation } \\
\text { almost normal. }\end{array}$ & $\begin{array}{l}\frac{1}{3} \\
\frac{2}{3}\end{array}$ & $\begin{array}{l}\frac{2}{3} \\
\frac{1}{3}\end{array}$ \\
\hline \multirow[t]{2}{*}{18 to 26 hours } & $\begin{array}{l}\text { White, granular tubules with no visible lumina or flow } \\
\text { intermixed with: }\end{array}$ & $\frac{1}{3}$ & $\frac{2}{3}$ \\
\hline & $\begin{array}{l}\text { Tubules with various size lumina, clear tubular fluid, } \\
\text { granular epithelium. Some tubules with dark red casts. }\end{array}$ & $\frac{2}{3}$ & $\frac{1}{3}$ \\
\hline
\end{tabular}

* Observations were made in vivo under a dissecting microscope at $160 \times$.

Gross appearance of the kidney. The sequential changes in the appearance of the kidney surface after glycerol injection are summarized in Table I. There was moderate variation in the time at which hemoglobin first appeared in individual tubules of a single kidney that must be attributed to variation in glomerular filtration rates among nephrons in the first few minutes after glycerol in-

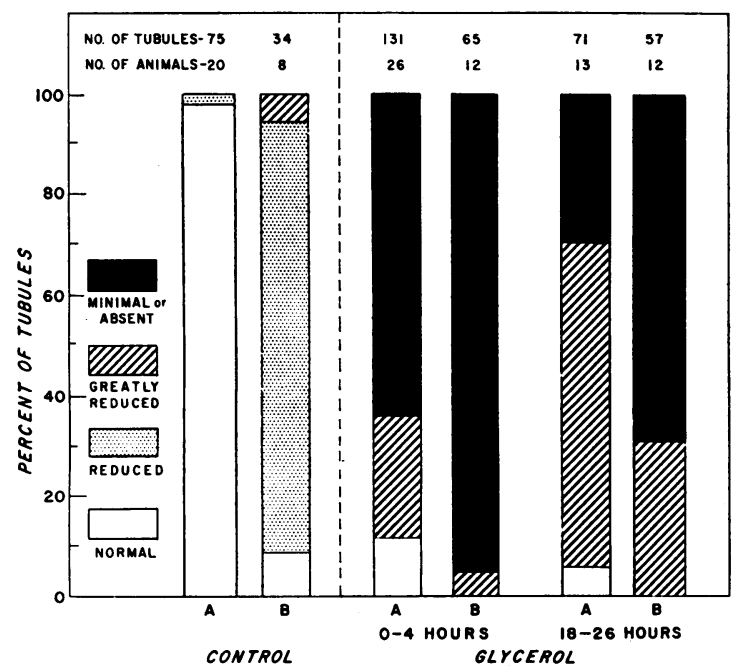

Fig. 1. Qualitative estimate of PRoximal tubular FLUID FLOW RATE IN CONTROL AND GLYCEROL-TREATED ANIMALS. Nondehydrated and dehydrated groups are designated $\mathrm{A}$ and $\mathrm{B}$, respectively. jection. The changes observed in dehydrated and nondehydrated rats were similar qualitatively, but were considerably more severe in the dehydrated animals. The improvement in the appearance of the nephrons was notably slower, and maximally involved tubules were seen approximately twice as frequently in these rats (see Table I).

The kidneys of 18 control animals that had been deprived of water for 24 hours before study were only slightly different from normal. Their tubular epithelium had a slightly granular appearance, and the peritubular capillary circulation of the surface vessels was thought to be minimally reduced. This appearance correlated with decreased glomerular filtration rate and tubular fluid flow rate, to be described later. There was little variation, if any, in the appearance of tubules of individual kidneys of these animals.

Tubular fluid flow rate. For the first 4 hours after rats were injected with glycerol, their proximal tubular fluid flow rate was markedly diminished. Flow in the majority of tubules was too slow to permit quantitative measurements, although considerable variation in flow was apparent. To document this variation, we made qualitative estimates of the rate of flow by observing the rate at which a small droplet of Sudan blackstained mineral oil passed down the tubule. Flow rates were judged to be normal, reduced, greatly 
reduced, and minimal or absent; the results in control animals and those that received glycerol are shown in Figure 1. Little variation in flow rate could be detected in tubules of individual kidneys of normal control and dehydrated control rats. Flow rate in the latter group uniformly appeared somewhat decreased in accord with the quantitative determinations described below. In the 4hour period after the intramuscular injection of glycerol, $63 \%$ of 131 tubules of 26 nondehydrated rats were judged to have minimal or absent flow, an additional $25 \%$ of tubules had variously reduced flow, and flow rate in the remainder was little different from normal. Quantitative measurements discussed below, however, did not reveal any tubules with normal proximal tubular fluid flow at this stage. Tubular fluid flow rate was more greatly reduced in animals that had been dehydrated for 24 hours before glycerol injection. Ninety-five per cent of 65 tubules of 12 rats had minimal or absent flow, and the remainder had seriously reduced flow.

From 18 to 26 hours after glycerol injection, qualitative estimates of tubular fluid flow rate were obtained in 71 nephrons of 13 nondehydrated rats. Twenty-nine per cent of tubules now had minimal or absent flow, whereas flow was variously reduced in an additional $65 \%$, and seemingly normal flow was found in $6 \%$ of nephrons. Flow was totally lacking in about two-thirds of nephrons of dehydrated glycerol-injected rats at this time, the vast majority of such nephrons being totally collapsed, whereas flow in the other third of the tubules was judged to be poor (Figure 1 ). The impairment of tubular fluid flow rate determined by this qualitative method correlated quite well with the degree of tubular abnormality seen under the dissecting microscope (Table I).

Quantitative measurement of proximal tubular fluid flow rate. When possible, the rate of tubular fluid flow in individual proximal tubules was determined directly from the volume of fluid that could be collected over a timed interval. Because an increasing fraction of the glomerular filtrate is absorbed as fluid passes along the proximal tubule, the rate at which fluid can be collected is related to the site at which fluid is aspirated. This site was not determined in all experiments performed in this series. We assumed that the distribution of collection sites in a large number of proximal tubules is sufficiently random to permit comparison of mean values in different experimental series. Mean flow rate in 29 proximal tubules of nine nondehydrated control animals was $17.3 \pm 1.2(\mathrm{SE}) \mathrm{m} \mu \mathrm{l}$ per tubule per minute (Table II), a value significantly higher than $9.2 \pm 0.8$ $\mathrm{m} \mu \mathrm{l}$ per tubule per minute obtained in 17 proximal tubules of eight dehydrated control animals $(\mathrm{p}<$ 0.001 ).

The rate of flow in tubules of a single kidney of nondehydrated hemoglobinuric animals was variable. In general, however, flow was so greatly decreased that fluid samples adequate for accurate measurement could be obtained only from those proximal tubules on the kidney surface that had the least abnormal appearance. The mean proximal tubular fluid flow rate in 15 tubules of nine nondehydrated rats studied 45 minutes to 4 hours after glycerol injection was $7.0 \pm 1.4 \mathrm{~m} \mu \mathrm{l}$ per tubule per minute, a value only $41 \%$ of that of nondehydrated control animals $(p<0.001)$. Eighteen to 26 hours after glycerol, proximal tubular fluid flow rate was $10.0 \pm 0.9 \mathrm{~m} \mu \mathrm{l}$ per tubule per minute, a value not significantly different from the 4-hour value, but greatly less than control values $(p<0.001)$. A meaningful number of samples adequate in size for accurate measurement could not be obtained from proximal tubules of dehydrated rats at either 4 hours or 18 to 26 hours after glycerol injection.

Glomerular filtration rate. GFR was determined from the clearance of ${ }^{14} \mathrm{C}$-labeled inulin in individual nephrons of normal and glycerol-injected animals. Mean GFR in 29 tubules of nine nondehydrated control rats was $38.8 \pm 2.2$ (SE) $\mathrm{m} \mu 1$ per tubule per minute (Table II), a value statistically indistinguishable from $42 \pm 2 \mathrm{~m} \mu \mathrm{l}$ per tubule per minute previously obtained in this laboratory (26). Interestingly, GFR measured in 17 tubules of eight rats that had been deprived of water for 24 hours averaged only $23.3 \pm 1.9 \mathrm{~m} \mu \mathrm{l}$ per tubule per minute, a value $41 \%$ less than that of the nondehydrated controls $(p<0.001)$.

Tubular fluid samples large enough for accurate measurement were difficult to obtain in nondehydrated rats studied from 45 minutes to 4 hours after glycerol injection. Mean GFR in 15 tubules of nine nondehydrated glycerol-injected rats was $14.7 \pm 2.3 \mathrm{~m} \mu \mathrm{l}$ per tubule per minute, a value significantly less than that of both nondehydrated and 
TABLE II

Tubular fluid flow rate, glomerular filtration rate, tubular fluid to plasma inulin concentration ratios, and absolute water absorption in individual nephrons 0 to 4 and 18 to 26 hours after glycerol injections

\begin{tabular}{|c|c|c|c|c|}
\hline \multirow[b]{2}{*}{ No. of tubules/No. of rats } & \multicolumn{2}{|c|}{ Control } & \multirow[b]{2}{*}{$\begin{array}{l}\text { Glycerol, } 0 \text { to } 4 \text { hours } \\
\text { Nondehydrated } \\
(15 / 9)\end{array}$} & \multirow[b]{2}{*}{$\begin{array}{c}\text { Glycerol, } 18 \text { to } 26 \text { hours } \\
\text { Nondehydrated } \\
(20 / 8)\end{array}$} \\
\hline & $\begin{array}{l}\text { Nondehydrated } \\
(29 / 9)\end{array}$ & $\underset{(17 / 8)}{\text { Dehydrated }}$ & & \\
\hline $\begin{array}{l}\text { Tubular fluid flow rate } \\
\text { (mul per tubule per minute })\end{array}$ & $17.3 \pm 1.2 \dagger$ & $9.2 \pm 0.8 \ddagger$ & $7.0 \pm 1.4 \ddagger$ & $10.0 \pm 0.9 \ddagger$ \\
\hline $\begin{array}{l}\text { Glomerular filtration rate } \\
\quad(\text { mul per tubule per minute })\end{array}$ & $38.8 \pm 2.2$ & $23.3 \pm 1.9 \ddagger$ & $14.7 \pm 2.3 \ddagger$ & $18.4 \pm 2.5 \ddagger$ \\
\hline $\mathrm{TF} / \mathrm{P}_{\mathrm{In}}{ }^{*}$ & $2.4 \pm 0.2$ & $2.7 \pm 0.2$ & $2.4 \pm 0.2$ & $1.8 \pm 0.1 \|$ \\
\hline $\begin{array}{l}\text { Absolute water absorption } \\
\quad(\text { mul per tubule per minute })\end{array}$ & $21.4 \pm 1.7$ & $14.1 \pm 1.6 \S$ & $9.1 \pm 1.5 \ddagger$ & $8.4 \pm 1.8 \ddagger$ \\
\hline
\end{tabular}

* Tubular fluid to plasma inulin concentration ratio.

$\dagger$ All values given are mean \pm standard error.

$\ddagger$ Statistically less than nondehydrated control value, $\mathrm{p}<0.001$.

Statistically less than nondehydrated control value, $\mathrm{p}<0.01$.

II Statistically less than nondehydrated control value, $\mathrm{p}<0.05$.

dehydrated control animals $(\mathrm{p}<0.001)$. Between 18 and 26 hours after glycerol injection mean GFR in 20 tubules of eight nondehydrated rats was $18.4 \pm 2.5 \mathrm{~m} \mu \mathrm{l}$ per tubule per minute, a value significantly less than that of nondehydrated controls $(p<0.001)$. It must be stressed, however, that this figure was derived from tubules with the least abnormal appearance and most rapid flow rate; flow was too slow in most of the remaining tubules to permit accurate volume measurement and, therefore, GFR determination. An insufficient number of samples adequate in size for assessment of GFR could be obtained from dehydrated rats within the first 26 hours after glycerol injection.

Water absorption in the proximal tubule. Fractional water absorption was calculated from the tubular fluid to plasma inulin concentration ratio. The mean $T F / P_{\text {In }}$ of 29 samples obtained from nine nondehydrated control rats was $2.4 \pm 0.2$ (SE), a value not significantly different from $2.7 \pm 0.2$, the mean of 17 samples obtained from eight dehydrated control animals (Table II). Fractional water absorption measured in 15 tubules of ten nondehydrated rats between $45 \mathrm{~min}$ utes and 4 hours after glycerol injection was $2.4 \pm$ 0.2 , a value indistinguishable from that obtained in the control period. Eighteen to 26 hours after glycerol injection, however, the $\mathrm{TF} / \mathrm{P}_{\text {In }}$ in 20 tubules of eight nondehydrated rats was reduced to $1.8 \pm 0.1(p<0.05)$. Fractional water absorption values in 15 tubules of six control nondehy- drated and in 9 tubules of five control dehydrated rats, and 9 tubules examined from 1 to 4 hours after glycerol injection in six nondehydrated rats, are shown as a function of the site of tubular puncture in Figure 2, A. Whereas these curves are not significantly different from one another, a significant decrease in water absorption measured in 12 tubules of six nondehydrated rats was seen 18 to 26 hours after the induction of acute renal failure (Figure 2, B).

Mean value for absolute water absorption of nondehydrated control rats, calculated from the fractional water absorption and the GFR, was $21.4 \pm 1.7 \mathrm{~m} \mu \mathrm{l}$ per tubule per minute (Table II). Although fractional water absorption was not different in dehydrated control rats, the considerably lower GFR in these animals resulted in a decreased absolute water absorption rate of $14.1 \pm$ $1.6 \mathrm{~m} \mu \mathrm{l}$ per tubule per minute $(\mathrm{p}<0.01)$. Again, because of the greatly reduced GFR, absolute water absorption of nondehydrated rats in the 4-hour period after glycerol injection was considerably less than that of controls $(p<0.001)$; a mean of $9.1 \pm 1.5 \mathrm{~m} \mu \mathrm{l}$ per tubule per minute was obtained. Such animals studied 18 to 26 hours after glycerol injection had a mean absolute water absorption rate of $8.4 \pm 1.8 \mathrm{~m} \mu \mathrm{l}$ per tubule per minute. As before, it should be recognized that the value obtained reflects only those tubules with the least abnormal appearance, a patent lumen, and a tubular flow rate that was adequate for accurate measurement. 


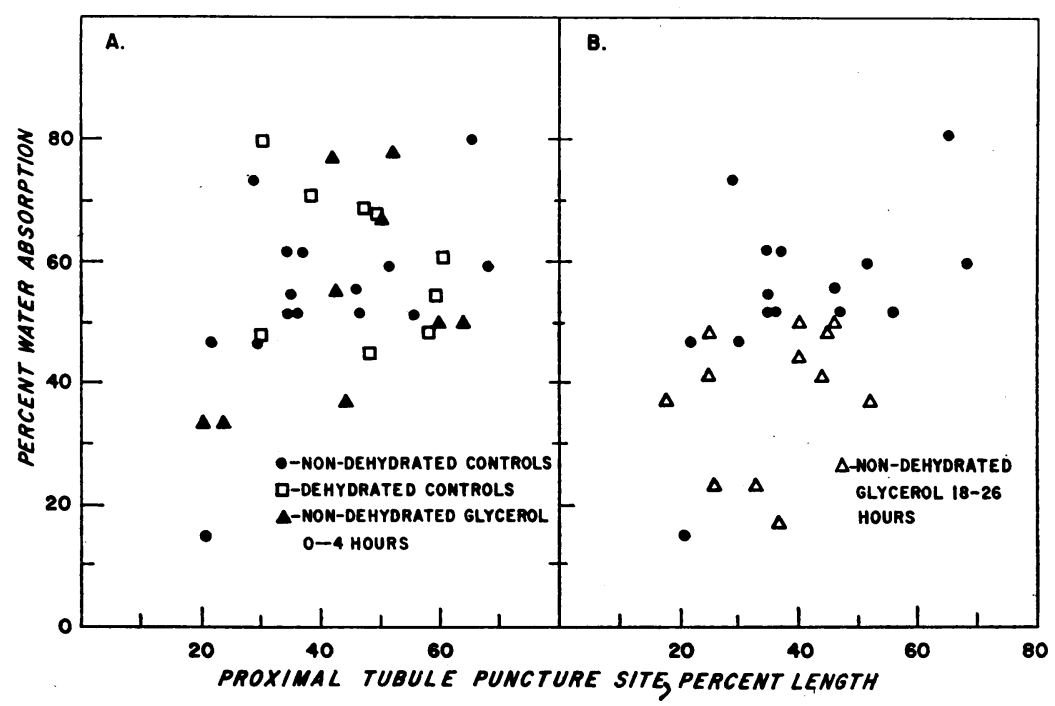

Fig. 2. Percentage of Filtered Volume absorbed in INDividual Proximal TUBULES RELATED TO SITE OF SAMPLE COLLECTION. No significant difference in water absorption is seen in the groups depicted in Figure 2, A. Water absorption is significantly reduced, however, 18 to 26 hours after glycerol injection, as shown in Figure 2, B.

To assess water absorption directly without the use of inulin, the rate of absorption of a segment of tubular fluid between two oil droplets was estimated in tubules exhibiting varying degrees of abnormality. No difference in water absorption between dehydrated and nondehydrated control rats could be detected by this gross method. In the 4-hour period after glycerol injection, 18 observations were made in six nondehydrated rats and 12 in six dehydrated rats. In each instance, the rate of tubular fluid absorption was considered to be decreased. Water absorption 18 to 26 hours after glycerol injection was judged to be decreased in eight, and normal or nearly normal in 7 tubules of five nondehydrated rats. It was greatly diminished in 8 tubules of five dehydrated glycerol-treated rats studied at this time. In no instance was an increased rate of absorption of proximal tubular fluid observed.

Proximal tubular hydrostatic pressure. Proximal tubular hydrostatic pressure in 71 nephrons of ten nondehydrated control rats was $15.5 \pm 0.1$ (SE) $\mathrm{cm} \mathrm{H}_{2} \mathrm{O}$, a value almost identical with that found in an earlier series (26). The mean pressure in 51 proximal tubules of ten dehydrated control rats was $15.0 \pm 0.2 \mathrm{~cm} \mathrm{H}_{2} \mathrm{O}$, a pressure slightly less than that of nondehydrated control rats, significant at the $5 \%$ confidence limit (Figure 3). Fifteen minutes to 4 hours after glycerol injection, proximal tubular hydrostatic pressure decreased greatly. The decrease was more marked in dehydrated than nondehydrated animals $(\mathrm{p}<$ $0.001)$, the mean of 81 measurements in 19 non-

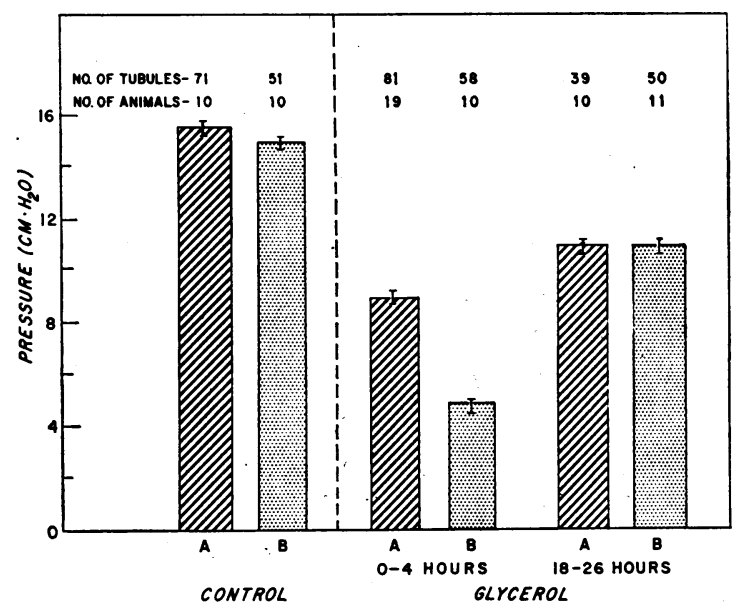

Fig. 3. Proximal tubúlar intraluminal hydroSTATIC PRESSURE IN CONTROL AND GLYCEROL-TREATED ANIMALS. The number of nephrons and animals is indicated above each column. Nondehydrated and dehydrated groups are designated $\mathrm{A}$ and $\mathrm{B}$, respectively. The bar at the top of each column represents 1 SEM. 
dehydrated rats being $9.0 \pm 0.1 \mathrm{~cm} \mathrm{H}_{2} \mathrm{O}$, whereas that found in 58 measurements from ten glycerolinjected, dehydrated rats was $4.8 \pm 0.3 \mathrm{~cm} \mathrm{H}_{2} \mathrm{O}$. These values were derived from tubules that had a lumen of sufficient size to permit the accurate assessment of intratubular pressure. Although the intratubular pressure of tubules lacking a distinct lumen could not be ascertained with certainty, the fact that it usually was possible to inject fluid into these tubules at a pressure of 1 to $5 \mathrm{~cm} \mathrm{H}_{2} \mathrm{O}$ indicates that external compression alone was not responsible for the collapse of their lumina. Hemoglobin-stained fluid present in most tubules with visible lumina during this period often could be washed down the tubular lumen with isotonic saline injected at physiologic intratubular pressures ( 15 to $20 \mathrm{~cm} \mathrm{H}_{2} \mathrm{O}$ ). As the tubular fluid flow rate progressively decreased with time, however, hemoglobin casts were less easily dislodged. Since the intratubular pressure of nephrons containing such casts remained low, the persistence of these casts appeared to be the result of a primary decrease in flow rate, rather than the cause of it. Proximal tubular hydrostatic pressure was still subnormal when measured 18 to 26 hours after glycerol injection. The mean value of 39 nephrons in ten nondehydrated rats was $10.5 \pm$ 0.7 ( $\mathrm{SE}$ ) $\mathrm{cm} \mathrm{H}_{2} \mathrm{O}$. Fifty measurements of hydrostatic pressure in 11 dehydrated animals also had a mean value of $10.5 \pm 0.4 \mathrm{~cm} \mathrm{H}_{2} \mathrm{O}$. The identity of the means is rather misleading, however. Pressure measurements could be made in most tubules of nondehydrated animals studied at this time; the given value thus represented the mean of most of the nephron population. By contrast, pressure was measurable in only a minority of tubules of dehydrated glycerol-injected rats. White granular tubules with no visible lumen predominated on the kidney surface of dehydrated animals, and intratubular pressure in such tubules was unmeasurable by the method used. Fluid almost invariably could be injected into these tubules at a pressure less than $5 \mathrm{~cm} \mathrm{H}_{2} \mathrm{O}$, which is greatly less than $10.5 \mathrm{~cm} \mathrm{H}_{2} \mathrm{O}$ given for the less seriously involved tubules. Nonetheless, proximal tubular hydrostatic pressure measured at this time was considerably improved over the value obtained 4 hours after glycerol was injected in dehydrated rats $(p<0.001)$.

\section{Discussion}

Glycerol-induced hemoglobinuria has been used with increasing frequency as a means of causing acute tubular necrosis in experimental animals (31-38). The histologic lesions produced in this manner have been well described, and seem to be consistent from study to study. In appearance, distribution, and reversibility they closely resemble the lesions seen in the kidney of man with acute renal failure due to transfusion accidents or crush injury (33).

The mechanism by which glycerol injected intramuscularly or subcutaneously causes the functional and anatomic changes of acute renal failure is unknown. Glycerol itself is not toxic to tubular epithelium $(33,37)$, and hemoglobinuria per se has been shown not to cause acute renal failure in the rat $(38,39)$. Carroll, Kovács, and Tapp have postulated recently that glycerol predisposes to the development of acute tubular necrosis by producing a combination of hemoglobinuria and renal ischemia (38). These authors found marked and patchy ischemia of large segments of the renal cortex as long as 4 hours after glycerol was injected subcutaneously into rats, although Finckh did not find evidence of cortical ischemia in rat kidneys $2 \frac{1}{2}$ hours after a comparable dose of glycerol was injected (40). Shortly after the injection of glycerol in the present study, peritubular capillary and arteriolar flow on the kidney surface decreased to such an extent that the kidney blanched. The rats were not hypotensive, however; their mean blood pressure was little different from preinjection values. Although cardiac output and peripheral vascular resistance have not been measured under these experimental conditions, an increase in renal vascular resistance appears to be the most likely cause of such a severe decrease in renal blood flow.

Neurogenic and hormonal responses to pain may be suspected of playing a role in this phenomenon, since the rats showed obvious discomfort after glycerol was injected. The anesthetization with pentobarbital of a number of rats before, and for two or more hours after, glycerol injection did not, however, appear to modify the vascular response or prevent the subsequent development of acute renal failure in other rats not subjected to laparotomy (41). Of more likely significance is the fact that the intravenous injection of an otherwise 
innocuous dose of homologous hemoglobin has been shown by Carroll and his associates to cause marked cortical ischemia when associated with the acute sequestration of extracellular fluid in the peritoneal space (38). A comparable mechanism may be involved here. After glycerol was injected into the hind limbs of rats, their thighs became so greatly swollen that a rapid alteration in body fluid compartments must have occurred. Such a mechanism would readily explain the increased severity of the lesion seen in animals with body water contraction caused by 24 hours of water deprivation.

This relationship between the development of oliguric acute renal failure and dehydration has been reported to exist in other experimental models $(39,42)$, as well as in human disease $(43)$. The adverse effect of dehydration has been attributed to a direct effect of antidiuretic hormone $(\mathrm{ADH})$ on urinary concentration and flow rate in the distal segments of the nephron $(39,44,45)$. Neither of these features needs be present in the development of oliguric acute renal failure, however. Severe renal failure was induced in all of ten Valtin strain rats with congenital hypothalamic diabetes insipidus (46), which excreted daily volumes of maximally dilute urine greater than two-thirds of their body weight at the time that a standard dose of glycerol was injected (47). It is interesting to speculate on the possible role of renin in producing the observed changes, since plasma volume depletion is a potent stimulus for renin release (48). Since the renin-angiotension axis is said to have a profound effect upon renal vascular tone (49-52), an interrelationship between these mechanisms in the development of oliguric acute renal failure may quite properly be suspected.

The outstanding feature in this study of hemoglobinuric oliguria was the diminution or absence of proximal tubular fluid flow that persisted long after the peritubular circulation seemingly had returned to normal. Flow was so severely reduced in animals deprived of water for 24 hours before glycerol injection that it was impossible to collect proximal tubular fluid samples adequate in size for accurate measurement in collection periods lasting as long as 9 minutes. This is in sharp contradistinction to the finding in dehydrated control rats, which also were oliguric, but had reasonably good flow in the proximal tubule (Table I). The cause of the decreased tubular fluid flow rate observed in these experiments was studied whenever possible by measuring the glomerular filtration rate and water absorption in individual nephrons. Even in nondehydrated animals, however, such measurement could be performed only on tubules with the least abnormal appearance after glycerol was injected. The glomerular filtration rate measured in such tubules of individual kidneys of nondehydrated rats $45 \mathrm{~min}$ utes to 4 hours after glycerol injection averaged only $38 \%$ of control values, the true mean GFR of the entire surface nephron population undoubtedly being far lower. Despite considerable improvement in the appearance of the kidney and restitution of peritubular capillary flow, glomerular filtration measured 24 hours after glycerol injection was still greatly reduced (Table I). It should be remembered, however, that fewer than $30 \%$ of nondehydrated rats developed oliguria. Even in the absence of oliguria, therefore, the kidney responded to the intramuscular injection of glycerol with a sharp and prolonged decrease in GFR. GFR was judged to be minimal or absent in virtually all nephrons of the predictably oliguric or anuric dehydrated glycerol-injected rats studied in the 26-hour period after glycerol injection.

The leakage of inulin across damaged tubular epithelium in these experiments must be considered a possible source of error in the measurement of both GFR and water absorption. In addition, the low proximal tubular fluid flow rate that was found might be attributed to grossly increased water absorption in the manner suggested by the "passive backflow" theory (14). In these experiments, fractional water absorption calculated from the inulin concentration ratio was either normal or decreased. This finding was confirmed directly without resorting to the use of inulin, as the absorption of segments of tubular fluid isolated between two oil droplets in the proximal tubule of glycerol-injected rats never appeared to be increased. In the most abnormal-appearing tubules of dehydrated glycerol-injected rats, absorption was so slow as to be barely appreciable to the eye. It appears that, whereas the transtubular leakage of a certain amount of inulin cannot be disproved in these experiments, leakage of sufficient inulin to invalidate the conclusion that glomerular filtration rate is grossly diminished seems quite unlikely. 
It has been suggested that the glomerular filtration rate in acute renal failure is reduced as a result of tubular obstruction, either by intraluminal casts (8-10) or by compression resulting from interstitial edema (11). According to this hypothesis, glomerular filtration is decreased or abolished because of a raised intratubular hydrostatic pressure opposing glomerular capillary filtration pressure. Whereas the presence of partially or completely collapsed tubules may suggest tubular compression, the finding of greatly reduced intratubular pressure concurrent with normal or decreased water absorption by such nephrons excludes extrinsic pressure as the cause of tubular collapse and the observed decrease in GFR.

Although cast formation is found to be an integral part of the pathology in this model, "casts" observed in vivo frequently could be washed down the tubule with isotonic saline injected into the tubule at pressures equal to physiologic intratubular hydrostatic pressure. It was apparent that these casts would have been washed away if normal glomerular filtration rate and intratubular pressure had existed. With the passage of time, they frequently could not be dislodged at physiologic pressure, and, therefore, would appear to be potentially obstructive. Since, however, the hydrostatic pressure of the tubules in which they were contained invariably was low, their persistence is considered to be the result, rather than the initial cause, of the cessation of glomerular filtration.

The small volume of urine excreted by patients in acute renal failure has been said to be derived from a few normally functioning nephrons, the
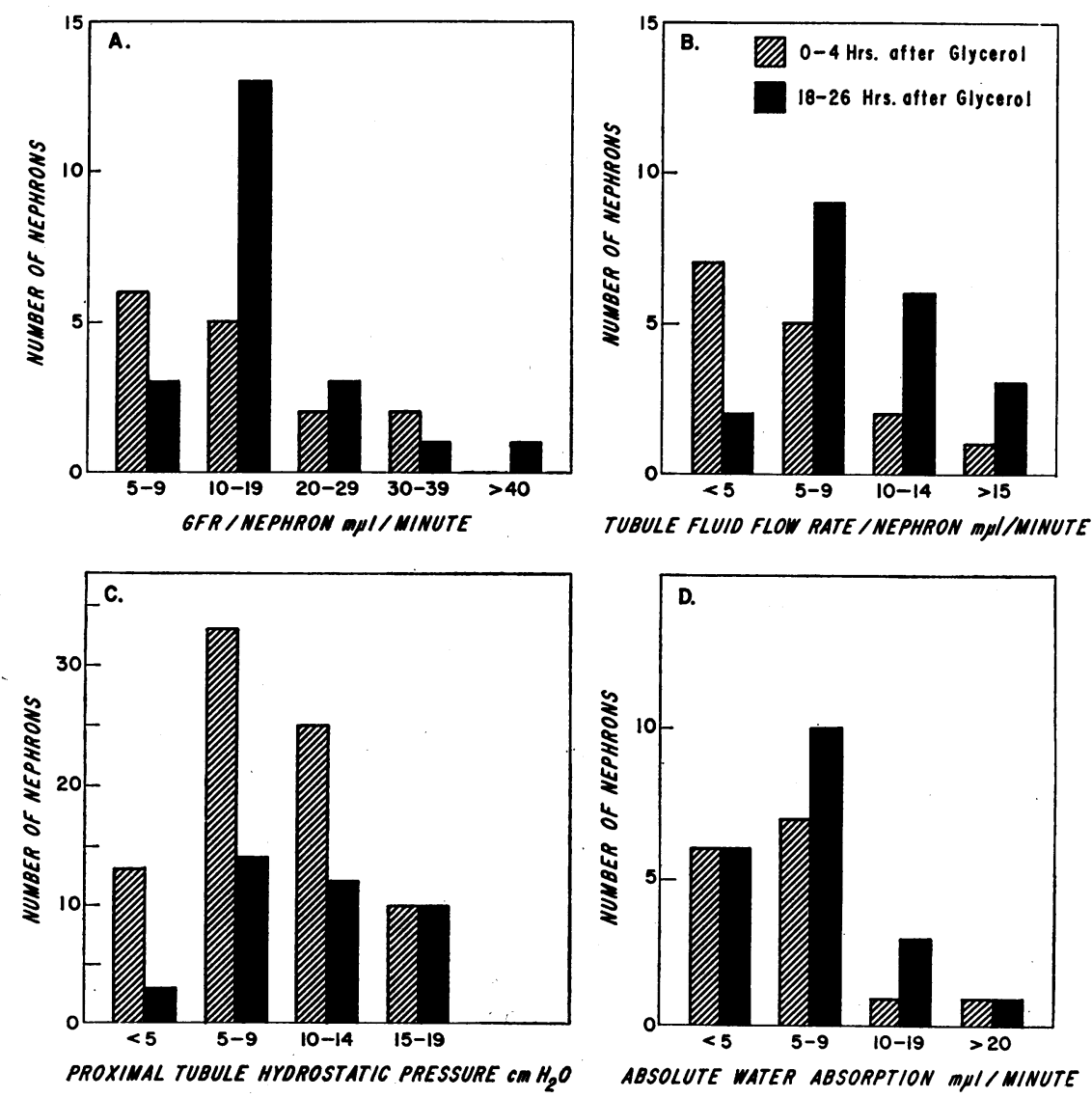

Fig. 4. SPectrum of abNormality of glomerular filtration Rate (GFR) (A) TUBULAR FLUID FLOW RATE (B), INTRALUMINAL HYDROSTATIC PRESSURE (c), AND ABSOLUTE WATER ABSORPTION (D). Nephrons could not be separated into only two groups, one totally nonfunctioning and one "intact"; a wide range of values was obtained in each parameter studied. 
remaining nephrons being nonfunctional (6). In the present study, normally functioning tubules were not found in oliguric rats with established acute renal failure. As shown in Figure 4, even nephrons of the less abnormal kidneys of nondehydrated rats could not be divided into normal and nonfunctioning populations, a spectrum of abnormality ranging from total nonfunction to a moderate decrease in GFR, with water absorption and intratubular pressure being observed.

A primary decrease in glomerular filtration rate of sufficient degree to fully explain the observed oliguria of glycerol-induced acute renal failure is apparent from this study. Since this was not due to either hypotension or tubular obstruction, another mechanism must be sought. The rate of glomerular filtration is related to the permeability of the glomerular barrier, the net transglomerular pressure gradient, and the viscosity of the filtrate. It is hard to envisage the virtually complete cessation of filtration seen in hemoglobinemic dehydrated rats resulting from an increase in blood viscosity alone, especially since a comparable change in blood viscosity undoubtedly occurred in nondehydrated rats, which generally had far greater filtration rates. Total renal blood flow was not measured in these experiments, but Conn, Wilds, and Helwig (24) and Brun and his associates (25), by using inert gas techniques, have found that total renal blood flow in experimental and human acute renal failure is not greatly diminished. Although severe renal ischemia was apparent in the first 4 hours after glycerol injection in the present experiments, the peritubular circulation of the nephrons accessible for micropuncture study thereafter was very adequate as judged by the eye. Neither an increase in total renal vascular resistance nor an effect of vascular shunts (21), therefore, appears likely to have played a significant role in the persistent diminution of GFR. An adequate total renal blood flow and normal arterial blood pressure do not necessarily connote a normal filtration pressure, however. According to current concepts, it is possible to modify glomerular filtration without significantly altering renal perfusion. Total renal blood flow is a direct function of arterial blood pressure and an inverse function of renal vascular resistance. Renal resistance, in turn, is represented essentially hy the sum of the afferent and efferent glomerular arteriolar and postglomerular capillary resistances. So long as the sum of these resistances remains constant, individual resistances can be adjusted in any manner without altering blood flow. The present finding of poor glomerular filtration with seemingly adequate blood flow is explicable, therefore, on the basis of afferent arteriolar constriction and equivalent efferent arteriolar dilation with a subsequent fall in intraglomerular filtration pressure. It is intriguing that the abnormalities in GFR, flow rate, hydrostatic pressure, and water absorption in the proximal tubule in these experiments mirror those found in mercury-induced acute renal failure (26), despite the great difference in the modes of renal injury in the two models.

\section{Summary}

The cause of oliguria in the early phase of glycerol-induced hemoglobinuric acute renal failure was sought by using micropuncture techniques. A greatly decreased proximal tubular fluid flow rate was found to be associated with oliguria. Neither increased absorption of glomerular filtrate nor obstruction of the tubules was responsible for this decrease in flow. Rather, an extreme reduction in glomerular filtration was found to account for the oliguria. Since intratubular pressure was reduced and the peritubular circulation of the surface nephrons available for micropuncture study was not judged to be greatly diminished, these findings are most logically attributed to an aberration in glomerular afferent-efferent arteriolar tone. A possible role of the renin-angiotension axis in this mechanism merits exploration.

\section{References}

1. Baker, S. L., and E. C. Dodds. Obstruction of the renal tubules during excretion of hæmoglobin. Brit. J. exp. Path. 1925, 6, 247.

2. DeGowin, E. L., H. F. Osterhagen, and M. Andersch. Renal insufficiency from blood transfusion. I. Relation to urinary acidity. Arch. intern. Med. 1937, 59, 432.

3. Bywaters, E. G. L., and J. K. Stead. The production of renal failure following injection of solutions containing myohæmoglobin. Quart. J. exp. Physiol. 1944, 33, 53.

4. Harrison, H. E., H. Bunting, N. K. Ordway, and W. S. Albrink. The pathogenesis of the renal injury produced in the dog by hemoglobin or methemoglobin. J. exp. Med. 1947, 86, 339. 
5. Flink, E. B. Blood transfusion studies. III. The relationship of hemoglobinemia and of the $\mathrm{pH}$ of the urine to renal damage produced by injection of hemoglobin solutions into dogs. J. Lab. clin. Med. 1947, 32, 223.

6. Meroney, W. H., and M. E. Rubini. Kidney function during acute tubular necrosis: clinical studies and a theory. Metabolism 1959, 8, 1.

7. Shaldon, S., H. Silva, T. R. Lawson, and J. G. Walker. Measurement of renal red cell and plasma transit times in acute renal failure. Proc. Soc. exp. Biol. (N. Y.) 1963, 112, 359.

8. Goldberg, M. Studies of the acute renal effects of hemolyzed red blood cells in dogs including estimations of renal blood flow with krypton. J. clin. Invest. 1962, 41, 2112.

9. Mason, A. D., Jr., P. E. Teschan, and E. E. Muirhead. Studies in acute renal failure. III. Renal histologic alterations in acute renal failure in the rat. J. surg. Res. 1963, 3, 450.

10. Menefee, M. G., C. B. Mueller, T. B. Miller, J. K. Myers, and A. L. Bell. Experimental studies in acute renal failure. II. Fine structure changes in tubules associated with renal failure induced by globin. J. exp. Med. 1964, 120, 1139.

11. Merrill, J. P. Kidney disease: acute renal failure. Ann. Rev. Med. 1960, 11, 127.

12. Abeshouse, B. S. Renal decapsulation: a review of the literature and a report of ten cases. J. Urol. (Baltimore) 1945, 53, 27.

13. Peters, J. T. Oliguria and anuria due to increased intrarenal pressure. Ann. intern. Med. 1945, 23, 221.

14. Richards, A. N. Direct observations of change in function of the renal tubule caused by certain poisons. Trans. Ass. Amer. Phycns 1929, 44, 64.

15. Dunn, J. S., M. Gillespie, and J. S. F. Niven. Renal lesions in two cases of crush syndrome. Lancet $1941,2,549$.

16. Oliver, J., M. MacDowell, and A. Tracy. The pathogenesis of acute renal failure associated with traumatic and toxic injury. Renal ischemia, nephrotoxic damage and the ischemuric episode. J. clin. Invest. 1951, 30, 1307.

17. Redish, J., J. R. West, B. W. Whitehead, and H. Chasis. Abnormal renal tubular back-diffusion following anuria. J. clin. Invest. 1947, 26, 1043.

18. Friedman, S. M., R. L. Johnson, and C. L. Friedman. The pattern of recovery of renal function following renal artery occlusion in the dog. Circulat. Res. 1954, 2, 231.

19. Sims, E. A. H., I. Goldberg, J. R. Kelly, and B. Sisco. Glomerular perfusion during acute renal insufficiency from mercury poisoning in the rat. J. Lab. clin. Med. 1959, 54, 440.

20. Bull, G. M., A. M. Joekes, and K. G. Lowe. Renal function studies in acute tubular necrosis. Clin. Sci. 1950, 9, 379.
21. Trueta, J., A. E. Barclay, P. M. Daniel, K. J. Franklin, and M. M. L. Prichard. Studies of the Renal Circulation. Oxford, Blackwell, 1947, p. 138.

22. Sheehan, H. L., and J. C. Davis. Renal ischæmia with failed reflow. J. Path. Bact. 1959, 78, 105.

23. Gomori, P., Z. Nagy, and I. Jakab. The problem of the arterio-venous anastomoses in the kidney. I. Renal extraction of $\mathrm{PAH}$ and $\mathrm{O}_{2}$ in dehydration, haemorrhagic hypotension and arterial hypoxia. Acta med. Acad. Sci. hung. 1964, 20, 153.

24. Conn, H. L., Jr., L. Wilds, and J. Helwig. A study of the renal circulation, tubular function and morphology, and urinary volume and composition in dogs following mercury poisoning and transfusion of human blood. J. clin. Invest. 1954, 33, 732.

25. Brun, C., C. Crone, H. G. Davidsen, J. Fabricius, A. Tybjaerg-Hansen, N. A. Lassen, and O. Munck. Renal blood flow in anuric human subject determined by use of radioactive krypton 85 . Proc. Soc. exp. Biol. (N. Y.) 1955, 89, 687.

26. Flanigan, W. J., and D. E. Oken. Renal micropuncture study of the development of anuria in the rat with mercury-induced acute renal failure. J. clin. Invest. 1965, 44, 449.

27. Vargas, R., and E. J. Cafruny. Effects of mercurial compounds on renal perfusion pressure. J. Pharmacol. exp. Ther. 1962, 135, 112.

28. Gentzkow, C. J. An accurate measurement for the determination of blood urea nitrogen by direct nesslerization. J. biol. Chem. 1942, 143, 531.

29. Wirz, H. Druckmessung in Kapillaren und Tubuli der Niere durch Mikropunktion. Helv. physiol. pharmacol. Acta 1955, 13, 42.

30. Bott, P. A. Renal excretion of creatinine in necturus. A reinvestigation by direct analysis of glomerular and tubule fluid for creatinine and inulin. Amer. J. Physiol. 1952, 168, 107.

31. Cameron, G. R., and E. S. Finckh. The production of an acute haemolytic crisis by the subcutaneous injection of glycerol. J. Path. Bact. 1956, 71, 165.

32. Finckh, E. S. Experimental acute tubular nephrosis following subcutaneous injection of glycerol. J. Path. Bact. 1957, 73, 69.

33. Finckh, E. S. The indirect action of subcutaneous injections of glycerol on the renal tubules in the rat. J. Path. Bact. 1959, 78, 197.

34. Fajers, C. M. Experimental studies in hemoglobinuric nephrosis. Part I. The effect on the kidneys of acute hemolytic anemia (hemoglobinemia) induced by subcutaneous injection of a single dose of glycerol. Acta Soc. Med. upsalien. 1958, 63, 225.

35. Fajers, C. M. Experimental studies in hemoglobinuric nephrosis. Part 2. The enhanced effect on the kidneys of glycerol-induced hemoglobinemia combined with unilateral nephrectomy. Acta path. microbiol. scand. 1959, 46, 17. 
36. Fajers, C. M. Experimental studies in hemoglobinuric nephrosis. Part 3 . The effect of acute hemolytic anemia (hemoglobinemia) combined with ten minutes' unilateral renal ischemia on the morphology and function of the rabbit's kidneys. Acta path. microbiol. scand. 1959, 46, 177.

37. Dallner, G., and J. L. E. Ericsson. Studies on oxidative enzyme systems of the rat kidney after haemolysis and haemoglobinuria. Acta path. microbiol. scand. 1964, 61, 333.

38. Carroll, R., K. Kovács, and E. Tapp. The pathogenesis of glycerol-induced renal tubular necrosis. J. Path. Bact. 1965, 89, 573.

39. Mason, A. D., Jr., J. W. Alexander, and P. E. Teschan. Studies in acute renal failure. I. Development of a reproducible lesion in experimental animals. J. surg. Res. 1963, 3, 430.

40. Finckh, E. S. Glycerol-induced oliguria and reduced glomerular filtration in the rat. Brit. J. exp. Path. 1965, 46, 119.

41. Wilson, D. R., M. L. Arce, and D. E. Oken. Clinical features of glycerol-induced acute renal failure in the rat. In preparation.

42. Maluf, N. S. R. Factors inducing renal shut-down from lysed erythrocytes: an experimental study. Ann. Surg. 1949, 130, 49.

43. Franklin, S. S., and J. P. Merrill. Acute renal failure. New Engl. J. Med. 1960, 262, 711.
44. Owen, K., R. Desautels, and C. W. Walter. Experimental renal tubular necrosis-the effect of Pitressin. Surg. Forum 1953, 4, 459.

45. Myers, J. K., T. B. Miller, C. B. Mueller, and D. Storrs. The role of $\mathrm{ADH}$ in experimental acute renal failure (abstract). Fed. Proc. 1963, 22, 661.

46. Sawyer, W. H., H. Valtin, and H. W. Sokol. Neurohypophysial principles in rats with familial hypothalamic diabetes insipidus (Brattleboro strain). Endocrinology 1964, 74, 153.

47. Arce, M. L., D. R. Wilson, and D. E. Oken. Oliguric acute renal failure in rats with complete hypothalamic diabetes insipidus. In preparation.

48. Winer, B. M. Personal communication.

49. McGiff, J. C., and D. M. Aviado. Differential response of renal and femoral blood flows and vascular resistances. Hypotensive and hypertensive procedures. Circulat. Res. 1961, 9, 1327.

50. Assali, N. S., and A. Westersten. Regional flowpressure relationship in response to angiotensin in the intact dog and sheep. Circulat. Res. 1961, 9, 189.

51. Mandel, M. J., and L. A. Sapirstein. Effect of angiotensin infusion on regional blood flow and regional vascular resistance in the rat. Circulat. Res. 1962, $10,807$.

52. McGiff, J. C., and H. D. Itskovitz. Loss of the renal vasoconstrictor activity of angiotensin II during renal ischemia. J. clin. Invest. 1964, 43, 2359. 